\title{
Egypt's Contribution DuRing the War to Protection against Disease Through Care of Eyes of Babies \\ EGYPT'S CONTRIBUTION DURING THE WAR TO PROTECTION AGAINST DISEASE THROUGH CARE OF EYES OF BABIES*
}

BY

\author{
Farid Massoud
}

CAIRO

ONE achievement Egypt contributed during the war for protection against disease stands out distinct and clear. It received the seemingly inappropriate but wholly adequate name of Care of Eyes of Babies which told very little but signified a good deal. For it is to be remembered that the importance of care of eyes of babies lies not only in protection against ophthalmia and trachoma, essential as this is, but in extending much farther in the spheres of general sanitation. It is very much connected with pure water, the fight against dirt and flies, the enlightenment of the mothers, and in fact with all the general hygienic requisites.

The condition of health in the eyes of babies in a locality is a reliable indicator for estimating the degree of good sanitation and salubrity in that locality and furthermore, in instituting care of eyes of babies in a locality, the solid foundations of good sanitation are thereby instituted there and a rise in the standard of general health is a sure consequence.

To understand what was achieved in this direction, it is necessary to go back a little and contemplate the time at the beginning of the war. There was then the general feeling shared by all workers in the spheres of preventive medicine in the country, concerned with taking up of new responsibilities that began with the arrival of our guests, the troops of the allied armies. It was incumbent on the internist as well as on the ophthalmologist to exert more of vigilance and pay more than the usual attention so that the standard of protection against disease be at a satisfactory level and at the highest possible degree. This inconspicuous and silent endeavour existing within the boundaries of individual activities was soon to be made visible and solid. Dr. Ali Ibrahim Pasha, on the advice of the Egyptian Government Health Expert, took the initiative and as Minister of Health then, called up the formation of a committee, to make a study and report on the question of protection against ophthalmia and especially trachoma in Egypt.

The committee was formed from eminent scientists, Mazni Bey, Tewfik Bey, Dr. Wilson, Riad Bey and Taher Bey. They had several meetings and presented their report in October, 1941. The whole problem was dealt with in a very comprehensive and far

- Received for publication, October 24, 1945. 
reaching way in the light of a detailed paper dealing with this subject and published in the "Egyptian Gazette "' on September 23rd, 1941. Care of eyes of babies was given the first place, being considered the basis of the whole work. The committee strongly recommended and insistently, advised the care of eyes of babies from the time of birth up to five years of age.

To extend this basic undertaking over the whole land, the report further advised an increase in the number of health centres and ophthalmic clinics in the whole country, considering that the fight against trachoma and ophthalmia would go hand in hand with all the other works of medicine, all aiming together at the raising of the general standard of health. Several other points were taken up also in the report, all of which received the attention due to them in their corresponding circles. One outstanding achievement that followed immediately after deserves to be especially mentioned as it constituted the next step in the realisation of this all inclusive plan of protective medicine. This was the promulgation of the Law of Rural Health Reform in 1942 through the extensive work of the late Dr. Abdel-Wahid Elwakil Bey, thus assuring a continuous and steady increase in the number of units and medical centres in both rural and urban districts.

And now that all this is made clear, let us look at the present state of care of babies' eyes. The babies are brought at the present time to Government and other child welfare centres, by their mothers without undue urging, once a week at least, beginning from the age of three weeks after birth. The mothers listen to the simple talks addressed to them by the special nurse and seem to be happy to put themselves under the guidance of the authorities in everything that pertains to hygienic measures. Those are the mothers on whom lies really the burden of the fight against disease. They are already provided with instructions by way of their babies. For the sake of these babies, the mothers co-operate in health reforms and give their indispensable aid in the work of protection against disease.

The figures of attendance in Government welfare centres reached $1,354,967$ in 1944 . In the ophthalmic hospitals, a still higher number of attendances was reached for babies less than five years of age who received treatment and care of eyes during the year. If statistics are extended to other state and national institutes caring for eyes of babies in the country, it will be found that the total reached four millions.

One possibility can be seen as coming to be realised for the first time in the very near future. It is the existence of trachoma-free schools. As can well be ascertained, there are sufficient pupils, teachers and attendants who have a healthy state of the eyes with regard to trachoma, to the extent of making possible the assignment 
of some of the existing schools solely to them, and restricting future admission to those who are free from the first stages of trachoma, or in other words those who are practically cured from it.

The obvious good effects resulting can well be judged from now, as the urge is created in the pupils who are refused admission to these privileged schools, to attain higher and higher standards of eye hygiene and of general health. These pupils and their families will exert themselves more and more in the field of protection against disease.

Another step forwards in this direction seems to be also coming in the very near future. This is legislation for care of eyes of babies. When this comes, as it is bound to come sooner or later, it will be the official recognition of the existing state. The work is already proceeding and is steadily gaining in speed and momentum.

The final word in this record of work is a look forward to the time that is coming soon, for what the ophthalmologists of Egypt may be able to achieve as trachoma experts in the fields of antitrachoma work that will be opening up.

Care of eyes of babies will still be the heading that will crown all the protective measures against transference of the disease to healthy localities from regions other than Egypt that are afflicted with trachoma.

The statistics given in the following tables show the condition of the conjunctiva in its relation to health and disease. The cases examined were from Government child-welfare centres, children's classes, primary boys' and girls' schools and secondary boys' schools. As far as could be ascertained, no lengthy treatment was undertaken immediately before the dates of examination of the eyes and so these tables may be considered as accurate estimates of the condition present now, in a great part of the population of Egypt that are living under certain circumstances. In the first table, the number of cases examined was 123 . The ages were from 3 weeks to 4 years. The first age in which an appearance of trachoma in the lids was manifest was noted to be about 6 months. From 3 weeks to 6 months, healthy conjunctiva was seen in ahout 60 per cent. of the cases. In the remaining 40 per cent. a minimum of attention and care would be sufficient to protect the eyes against ophthalmia and trachoma or to render the conjunctiva healthy again. From the age of 6 months to 4 years, healthy conjunctiva was seen in about 40 per cent. of the cases. With care during the first period as stated before the number of healthy cases will steadily be on the increase.

In the second table, the number of cases examined was 1,229 . The ages were from 4-8 years. The percentage of healthy conjunctiva reached as high as 80 per cent in some cases. In the third 
TABLE I

Condition of The Conjunctiva in Different Ages Abbassia and Sharabia Child Welfare Centres

\begin{tabular}{|c|c|c|c|c|c|c|}
\hline Age & Total & Healthy & $\mathbf{T}_{1}$ & $\mathbf{T}_{2}$ & $\mathrm{~T}_{3}$ & $\begin{array}{l}\text { Per cent. } \\
\text { healthy }\end{array}$ \\
\hline 3 weeks to 3 months & 12 & 6 & 1 & - & - & 60 \\
\hline 3 to 6 months $\ldots$ & 12 & 4 & 1 & - & - & - \\
\hline 6 months to 1 year... & 24 & 4 & 15 & 1 & 2 & $\longrightarrow$ \\
\hline 1 to $1 \frac{1}{2}$ years $\ldots$ & -52 & 17 & 23 & 1 & 6 & 40 \\
\hline $1 \frac{1}{2}$ to 2 years & 16 & - & 8 . & 1 & 1 & - \\
\hline 2 to 4 years. & 7 & 1 & 2 & 1 & 2 & 一 \\
\hline
\end{tabular}

TABLE II

Abbassia Kindergarten and Primary School

\begin{tabular}{|c|c|c|c|c|c|c|c|}
\hline Age & & $\begin{array}{l}\text { No. of } \\
\text { cases. }\end{array}$ & Healthy & $\mathrm{T}_{1}$ & $\mathrm{~T}_{2}$ & $T_{3}$ & $\begin{array}{l}\text { Per cent. } \\
\text { with healthy } \\
\text { conjunctiva }\end{array}$ \\
\hline $\begin{array}{l}4-5 \text { years } \\
5-6 \text { years } \\
6-7 \text { years } \\
7-8 \text { years }\end{array}$ & $\begin{array}{l}\left\{\begin{array}{l}\text { girls } \\
\text { boys }\end{array}\right. \\
\left\{\begin{array}{l}\text { girls } \\
\text { boys }\end{array}\right. \\
\left\{\begin{array}{l}\text { girls } \\
\text { boys }\end{array}\right. \\
\left\{\begin{array}{l}\text { girls } \\
\text { boys }\end{array}\right.\end{array}$ & $\begin{array}{r}14 \\
-54 \\
43 \\
41 \\
38 \\
38 \\
78 \\
77 \\
924\end{array}$ & $\begin{array}{c}10 \\
42 \\
33 \\
30 \\
31 \\
28 \\
68 \\
248\end{array}$ & $\begin{array}{r}3 \\
5 \\
6 \\
7 \\
3 \\
3 \\
4 \\
24\end{array}$ & $\frac{-}{-}$ & $\begin{array}{r}1 \\
7 \\
4 \\
4 \\
3 \\
7 \\
3 \\
210\end{array}$ & $\begin{array}{l}72 \\
78 \\
77 \\
74 \\
81 \\
73 \\
90 \\
74\end{array}$ \\
\hline
\end{tabular}

TABLE III

$\frac{\text { Primary Abbassia Gamalia Sayeda Nafeisa }}{\text { Total Healthy } T_{1} T_{2}} T_{3} \begin{aligned} & \text { Per cent. } \\ & \text { Agealthy }\end{aligned}$

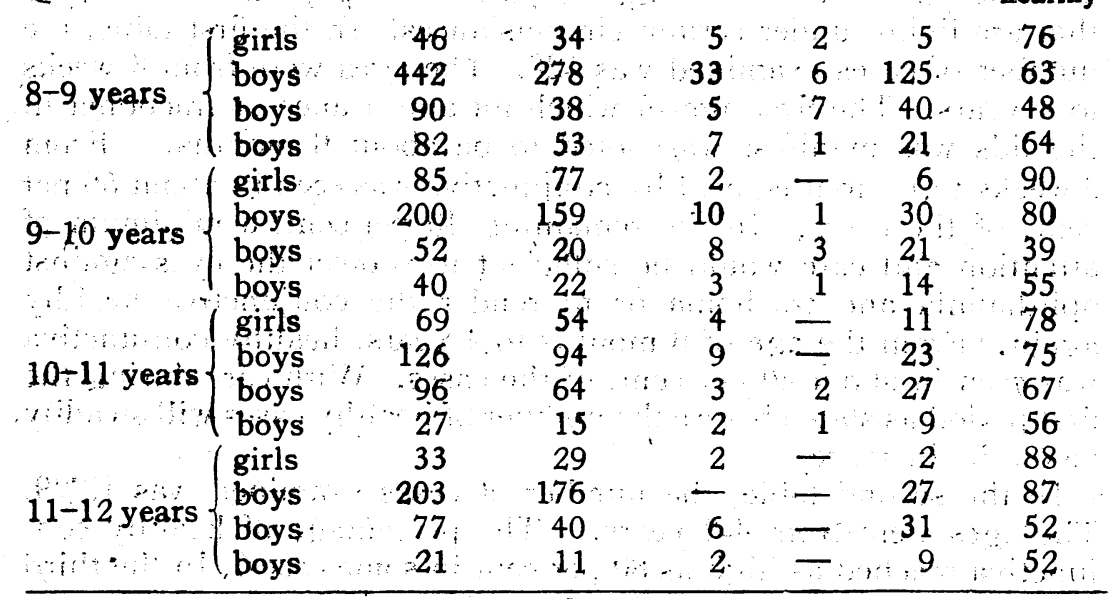


Egypt's Contribution During the War to Protection

Against Disease Through Care of Eyes of Babies

table the number examined was 1,467 , the ages were from 8-12 years and healthy conjunctiva was noticed to reach in some instances to 90 per cent.

This happy result is due no doubt to the hard and continuous efforts of the section concerned with the fight against trachoma in the schools, this together with the gradual enlightenment of the mothers.

\section{Anti-Trachoma Work in Egypt in its Relation to the Figat Against Other Diseases}

In the fight against trachoma in Egypt, as in no other disease perhaps, the collaboration of Anglo-Egyptian efforts has been effected with such marked and outstanding success.

It was in 1902 that the late Sir Ernest Cassel began work against trachoma in Egypt by his generous donation of $\Varangle 40,000$ given into trusteeship to the representative of the British Government in Egypt with this object, " to teach the principles of ophthalmic surgery to Egyptian surgeons in order that they may later on give their services gratuitously to relieve the suffering of their fellow countrymen from these prevalent eye diseases which result so frequently in blindness."

This object was successfully attained through the big efforts of A. F. MacCallan during a quarter of a century.

In 1925, the Imperial War Graves Commission gave $£ 6,600$ for erection of the Giza Ophthalmic Laboratory as memorial to the men of Egypt, Labour and Transport Corps, in the first great war. This laboratory, since then, has been giving most valuable work in the fight against trachoma.

Now, the extent of spread of trachoma in a locality is directly in proportion to the degree of sanitation there; the one is bound to affect the other as the two are so intimately connected together.

When the war began, this relationship was made use of to help in protection not only against ophthalmia and trachoma but also against disease in general, and this through active co-operation of the mothers.

In their carrying out hygienic instructions and measures for the care of the eyes of their babies, they managed not only to bring about a rapid raising of the standard of general health in the country but also to ensure protection against the spread of disease, an object so much desired at such a critical time when multitudes of allied troops were constantly arriving in Egypt, either to stay for some time or to proceed from there to other places.

Much of the credit of bringing this accomplishment about goes to the late Dr. A. W. Byrne, Health Expert to the Egyptian Government. On his advice, the Minister of Health called 
the formation of the Committee whose report submitted in October, 1941, constituted the plan of the work that was performed subsequently.

Special reference should be made here to the kind support to this work of H.E. Lady Jacqueline Lampson (Killearn).

For the details of the work achieved, the archives of P.H.M., Cairo, should be consulted. Only a brief outline is given in this paper, read at the meeting of the Ophthalmological Society of Egypt.

It is to be hoped that this traditional collaboration of efforts in the fight against trachoma will be continued not only in Egypt but also outside this country, on a wider scale, now that the war is over and bigger fields of anti-trachoma work will, soon be opening up.

\section{PROPTOSIS-DIFFERENTIAL DIAGNOSIS BY \\ FARID MASSOUD \\ CAIRO}

Diagnosis of cases of proptosis is of importance to the physician and surgeon as well as to the rhinologist and ophthalmologist. In fact, here is a problem which touches different fields of medicine and for which co-ordinate working of men of different specialities is often necessary.

By the term proptosis is meant a state of protrusion of the globe of the eye between the lids. Exophthalmos is synonymous. Beer suggested calling the affection exophthalmus when the protruded eye is in its natural state, exophthalmia when it is inflamed and exophthalmoptosis when the displacement is caused by division of the nerves and muscles of the orbit or by paralysis of the latter.

As is well known an end diagnosis of a case of proptosis is not always easy. For this reason, it will be found helpful if as a first step an attempt is made to place the case to be diagnosed in one of six main types or categories. These are :-1. Apparent; 2. Due to a congenital anomaly; 3 . Due to a traumatic injury; 4 . Due to an inflammatory process; 5 . Due to a new growth; 6. Due to systemic trouble or disease.

It will not be difficult usually to place a case, from the general examination and the history, in one of these main types, this notwithstanding the possibility of an overlapping, as in cases that are due to a trauma and inflammation together, or in cases that present a congenital origin with a new growth, etc. And so having

* Received for publication October 24, 1945. 